\title{
Desindustrialização: a crônica da servidão consentida*
}

\author{
Rodrigo Costa da Rocha Loures** \\ José Luis Oreiro ${ }^{* * *}$ \\ Carlos Artur Krïger Passos ${ }^{* * * *}$
}

Clausewitz afirmava que "não é no que pensamos, mas no como pensamos, que reside nossa contribuição à teoria". De fato, pensamos o Brasil como as finanças internacionais o determinam. O modelo de política econômica praticada no Brasil desde 1994 constitui um significativo exemplar de servidão consentida.

Baseado numa combinação perversa de juros altos, taxa de câmbio apreciada, tributação exorbitante e redução do gasto público em infra-estrutura - estamos progressivamente "conquistando a confiança internacional" e também o seu desinteresse, salvo em obter aqui algumas matérias-primas e commodities e, claro, ganhos financeiros de um povo que é submetido pelos seus governantes à felicidade de ser o pagador campeão mundial de juros.

Esta política econômica tem contribuído para um processo contínuo de desindustrialização precoce da economia, em um caminho sólido e seguro de servidão consentida. Com efeito, a produção física da indústria brasileira, segundo dados do Ipeadata, cresceu apenas 23\% no período entre 1991 e 2004, ou seja, o produto industrial brasileiro cresceu a uma taxa média 1,76\% ao ano nesse período; contrastando com um crescimento médio de 2,5\% do PIB no mesmo período. Embora ambos esses números sejam pífios, revelam de forma inequívoca que a economia brasileira passa por um processo de desindustrialização, isto é, por uma queda da participação da produção industrial no PIB.

Alguns economistas, escravos de um saber convencional desenvolvido em algumas universidades norte-americanas e européias, tendem a ignorar a importância deste fenômeno para as perspectivas de desenvolvimento da economia brasileira. Para eles, a indústria é apenas um setor entre outros, não possuindo nenhuma importância fundamental para o

\footnotetext{
* Documento apresentado na reunião de Diretoria da Confederação Nacional da Indústria - CNI - fev / 2006

** Administrador de Empresas, Empresário, Presidente da Federação de Indústrias do Estado do Paraná-FIEP, Presidente do Conselho Temático de Política Industrial e Desenvolvimento Tecnológico - COPIN da CNI.

*** Doutor em Economia (IE/UFRJ), Professor do Departamento de Economia da UFPR, Diretor do Centro de Pesquisas Econômicas da UFPR e Pesquisador do CNPq. Endereço eletrônico: joreiro@ufpr.br. Página Pessoal: http://www.joseluisoreiro.ecn.br.

**** Doutor em Economia (Université de Paris I - Panthéon-Sorbonne), Professor do Departamento de Economia da UFPR e Consultor. Endereço eletrônico: ckpassos@uol.com.br
} 
crescimento econômico de longo prazo. Dessa forma, a relação entre a taxa de crescimento da produção industrial e a taxa de crescimento do PIB não adquire nenhuma importância específica. O que importa, argumentam, é desenvolver mecanismos capazes de garantir uma elevada taxa de crescimento econômico, embora o resultado das políticas por eles implementadas tenha sido apenas a recessão e marasmo. Se esse hipotético crescimento será obtido por intermédio de um expressivo crescimento do setor industrial ou dos demais setores da economia é uma questão de importância secundária. Aliás, tudo é secundário quando o principal é manter tudo estavelmente estagnado. Elejam as senhoras e senhores, doutores ou operários, ou quem quer que seja.

Essa visão míope e ignorante acerca do papel da indústria, só surge nas "modernas teorias" elaboradas naqueles países onde a indústria já os desenvolveu. Ali onde o progresso técnico como elemento essencial da dinâmica das economias já se difundiu para todo o tecido industrial e ao conjunto da sociedade, o que, bem ou mal as caracterizam como modernas. A partir deste desenvolvimento industrial já alcançado, é evidente que as teorias ali desenvolvidas tendam a reforçar as condições de manutenção e estabilidade deste processo de expansão. Simplificadamente, eis como eles pensam. Aqui neste país, onde este processo não está autonomizado, pensar deste modo e adotar políticas decorrentes, repetimos, é consentir voluntariamente em nossa servidão.

Ignorar a crucial, específica e ainda não superada função dinamizadora da indústria não encontra respaldo nem na experiência histórica e nem nos desenvolvimentos mais recentes da teoria econômica. De fato, ao longo dos 250 anos de desenvolvimento do capitalismo não existe um único caso histórico de crescimento sustentado do PIB que não tenha sido liderado e/ou impulsionado por um maciço processo de industrialização.

O surgimento do capitalismo como modo de produção plenamente constituído por volta da segunda metade do século XVIII se confunde com o advento da Revolução Industrial Inglesa. A ascensão da Alemanha, dos Estados Unidos e do Japão à categoria de grandes potências econômicas no último quartel do século XIX também resultou do processo acelerado de industrialização que esses países experimentaram na segunda metade do século XIX. Por fim, o espetacular crescimento da economia brasileira no período 1930-1980 coincide com o processo de industrialização acelerada de nossa economia por intermédio do assim chamado modelo de substituição de importações.

No que tange à teoria econômica, tem havido uma mudança contínua na forma pela qual os economistas pensam o papel da indústria no processo de desenvolvimento 
econômico. Nesse contexto, os escritos de Lord Nickolas Kaldor da década de 1960 adquirem uma importância fundamental. Em duas lectures intituladas Causes of the Slow Growth of the United Kingdon (1966) e Strategic Factors in Economic Development (1967), Kaldor apresentou três leis fundamentais a respeito do crescimento de longo prazo das economias capitalistas ${ }^{1}$, quais sejam:

(i) Existe uma forte correlação positiva entre o crescimento do PIB e o crescimento da produção industrial, ou seja, os países que apresentam maior taxa de crescimento econômico são precisamente aqueles nos quais a produção industrial cresce mais rápida;

(ii) Existe uma forte correlação entre o crescimento da produção industrial e o crescimento da produtividade na indústria, ou seja, uma aceleração do ritmo de crescimento da produção industrial está associada a um aumento da taxa de crescimento da produtividade na indústria. A presença de economias de escala, estáticas e dinâmicas, nos permite afirmar que a relação de causalidade ocorre do crescimento da produção industrial para o crescimento da produtividade, isto é, um aumento da taxa de crescimento da produção industrial deverá causar um aumento da taxa de crescimento da produtividade na indústria;

(iii) Existe uma forte correlação positiva entre o crescimento da produção industrial e dos serviços voltados para a indústria ${ }^{2}$, e o crescimento da produtividade fora da indústria, notadamente no setor de serviços em geral, na agricultura e setores extrativistas. Isso porque tais setores estão sujeitos a rendimentos marginais decrescentes, ao passo que na indústria prevalecem rendimentos marginais constantes ou crescentes. Dessa forma, uma realocação da força de trabalho disponível da agricultura e do setor de serviços para a indústria deverá resultar num aumento da produtividade do trabalho no setor agrícola e de serviços, contribuindo para um aumento da produtividade do trabalho na economia como um todo.

Essas três leis do crescimento das economias capitalistas apontam para o papel preponderante do crescimento da produção industrial como motor do crescimento econômico de longo prazo. Nesse contexto, a questão fundamental a ser formulada é: que ou quais fatores determinam o ritmo de crescimento da produção industrial?

A teoria econômica e a experiência prática dos homens da indústria apontam para uma variável de importância fundamental na determinação do nível de produção, qual seja: a

\footnotetext{
${ }^{1}$ Para maiores informações, ver: Thirwall, A.P. (2002). The Nature of Economic Growth. Edward Elgar: Aldershot.

2 Neste texto, o termo indústria refere-se não apenas às unidades comumentemente classificadas como "indústria", mas também aos serviços voltados diretamente para a indústria, tais como os de softwares industriais, design, sistemas de gestão, etc, atualmente de modo crescente terceirizados.
} 
demanda efetiva pelos bens produzidos pela indústria. Numa economia capitalista moderna essa demanda efetiva pode ser gerada por intermédio do consumo doméstico e/ou por intermédio das exportações. Embora o consumo doméstico seja, em termos quantitativos, o componente mais importante da demanda efetiva nas economias capitalistas, assim como na brasileira, a sua dependência com respeito à massa salarial e, portanto, com respeito à renda que é gerada, em grande medida, no âmbito da própria indústria - fazem com que o consumo seja um elemento geralmente passivo do processo de crescimento econômico. Em outras palavras, aumento do consumo é a conseqüência, e não a causa, do crescimento econômico e do aumento da produção industrial. Dessa forma, a produção industrial pode aumentar, de forma persistente e autônoma, por intermédio de um aumento contínuo das exportações de produtos industrializados.

A taxa de crescimento das exportações de bens manufaturados depende, por sua vez, de duas variáveis fundamentais, a saber: a taxa de crescimento da renda do resto do mundo e do nível de competitividade da indústria vis-à-vis a suas congêneres no exterior. Dessas duas variáveis, apenas a competitividade pode ser objeto da política econômica nacional, embora seja evidente que adotar políticas que impedem um país de aproveitar momentos de auge expansivo mundial para aprofundar e intensificar sua industrialização constitui uma inexplicável opção. Podemos reconhecer que a existência efetiva e intensa de fatores externos/internos acentuadamente negativos produziu uma década perdida. Após uma brilhante - e absolutamente criativa - passagem de um forte regime inflacionário para uma relativa estabilidade dos preços, entregar-se ao marasmo por uma inexplicável submissão ideológica a uma cartilha inadequada, foi jogar fora outra década. Esta cartilha propõe soluções absolutamente heterodoxas, tais como manter taxas de juros, de curto e de longo prazo, em um patamar superior à taxa de retorno média do capital, algo tido pelos fundadores da ciência econômica desde Adam Smith como elemento inviabilizador das economias capitalistas no longo prazo.

Não há razões para manter uma política de financismo estéril que fortemente vem reduzindo os setores industriais de maior valor agregado quando exatamente as notáveis condições expansivas mundiais existentes permitiriam um adensamento do valor agregado industrial, a elevação significativa do emprego e da produtividade industrial e geral. Superar este caso de patologia psiquiátrica que constitui induzir todo um povo a uma postura rentista é necessário, para evitarmos desperdiçar uma terceira década. Ampliar a competitividade da indústria nacional exige a adoção de políticas específicas para três variáveis-chaves: a taxa de 
crescimento dos salários nominais, a taxa de crescimento da produtividade do trabalho na indústria e o nível da taxa de câmbio.

A experiência dos países europeus nos últimos 25 anos - principalmente no que se refere à performance superior dos países escandinavos (Suécia e Noruega) com respeito aos países da Europa Continental (França e Alemanha) em termos de taxa de desemprego - tem mostrado que um elemento fundamental para garantir a competitividade das exportações é a adoção de uma política de moderação salarial por parte dos sindicatos. Isso é o que vem sendo feito, em grande medida, pelos sindicatos dos trabalhadores dos países escandinavos, os quais, reconhecendo o seu próprio interesse nas atuais circunstancias, têm reivindicado reajustes salariais próximos ao ritmo de crescimento da produtividade do trabalho na indústria. O que de resto pode facilitar aos empresários e sindicatos com mais percepção da realidade, acordos mais estáveis quanto a emprego e salários, e um estímulo à partilha de lucros futuros provenientes de ganhos extras de produtividade.

No caso brasileiro, como as taxas salariais são comprimidas pelos excedentes estruturais de oferta de trabalho, as variáveis mais importantes para o fomento da competitividade das exportações são a taxa de crescimento da produtividade do trabalho na indústria e a taxa de câmbio, inclusive porque o nível de sindicalização dos trabalhadores brasileiros é muito inferior ao observado nos países europeus.

Nesse contexto, uma política econômica visando à aceleração do crescimento da economia brasileira deve necessariamente estimular a competitividade das exportações de produtos manufaturados por intermédio de medidas que (a) aumentem a taxa de crescimento da produtividade na indústria e (b) mantenham a taxa nominal de câmbio em patamares competitivos.

Para acelerar o ritmo de crescimento da produtividade na indústria, a teoria e a pesquisa econômica têm mostrado que esta é, em larga medida, positivamente estimulada pelo próprio crescimento da produção industrial, numa relação conhecida como lei de Verdoorn (cf. Thirlwall, 2002, p.43). Dessa forma, a adoção de uma política monetária recessiva na forma de elevadas taxas nominais e reais de juros por parte do Banco Central do Brasil contribui para desacelerar o ritmo de crescimento da produtividade na indústria, reduzindo assim a competitividade das exportações de manufaturados, à medida que tais políticas têm como efeito colateral óbvio a redução do ritmo de crescimento da produção industrial.

O que os doutores do financismo estéril jamais permitem discutir é que essas políticas recessivas, ao reduzir o ritmo de crescimento da produtividade na indústria, e em 
decorrência do próprio investimento industrial, perpetuam as pressões inflacionárias. Só o aumento da produtividade do trabalho na indústria - resultante em larga medida do crescimento da produção industrial, como também, da realização de investimentos que incorporam as novas tecnologias de produção - é que permite um aumento sustentado da taxa de crescimento do PIB sem a ocorrência de pressões inflacionárias.

O Banco Central cria assim um círculo vicioso; aumenta as taxa de juros para coibir pressões inflacionárias, gera quedas no ritmo de crescimento da produção industrial, da produtividade e do investimento na indústria - perpetuando, dessa forma - a razão pela qual o Banco Central "necessita", segundo eles próprios, manter as taxas de juros em patamares elevados, aliás elevadíssimos, para gáudio e sóbrios apoios à "coragem" do Bacen em manter esta austera política emitidos pelos setores rentistas nacionais e estrangeiros. Segue-se, portanto, que uma condição necessária para o aumento do ritmo de crescimento da indústria brasileira é o término da política monetária recessiva adotada permanentemente pelo Banco Central do Brasil. É compreensível também que o carro-chefe das demandas políticas dos financistas estéreis seja a da autonomia do Bacen. Parafraseando o poeta, podemos dizer que "o FMI é aquil"; os rentistas só precisam ainda autonomizá-lo com relação à democracia, evitando que algum político possa desejar, de fato, conduzir o país ao desenvolvimento, quebrando esta estabilidade de ganhos conquistada.

Outro fator importante para a competitividade das exportações de manufaturados é o nível da taxa nominal e real de câmbio. Embora ganhos sistemáticos de competitividade não possam ser obtidos por intermédio de desvalorização da taxa de câmbio, o bom senso indica que a taxa de câmbio deve ser mantida num patamar que não inviabilize o crescimento das exportações. Não foi o que aconteceu entre 1994 e 1999 com a economia brasileira, o que provocou um estúpido endividamento sem investimento correspondente, desabou na crise de 1999, e estabeleceu com ares de verdade teórica a falsa noção de que o Estado tem por finalidade extorquir recursos da população para pagar os juros que o próprio Estado decide ampliar em nome da confiança dos rentistas. Pensávamos ter aprendido que juros elevados e câmbio valorizado são venenos a evitar.

Eis que, nos últimos 18 meses, desde meados de 2004, a taxa nominal de câmbio vem apresentando uma exorbitante valorização, ainda não contida embora tenha sido reduzido o seu ritmo de valorização depois de abandonadas as platitudes de que 'câmbios flutuantes flutuam'. Este fenômeno resulta, além dos superávits comerciais de matérias-primas e commodities valorizados versus importações anêmicas de uma economia industrial que não 
cresce e não investe, também em larga medida, das inefáveis ou inexplicáveis elevadíssimas taxa de juros praticadas pelo Banco Central do Brasil. No patamar atual de cerca $\mathrm{R} \$ 2,12$ por dólar, o câmbio inviabiliza as exportações de manufaturados, corrói completamente a competitividade da indústria brasileira e contribui para a desaceleração do ritmo de crescimento da produção industrial.

Neste contexto, não deixa de ser surpreendente que tenhamos recentemente somado às benesses dos juros elevados a desoneração do imposto de renda aos aplicadores financeiros internacionais para as aplicações em títulos públicos. Estes novos recursos entrantes jamais chegarão às empresas produtivas, mas irão certamente aprofundar a sobrevalorização cambial em detrimento da produção e do investimento.

Cria-se um outro círculo vicioso no qual as combinações entre taxa real de juros elevada e câmbio apreciado destroem a competitividade, o crescimento da produção e da produtividade do setor industrial, e por não estimular o aumento da capacidade instalada através de investimentos, perpetua as pressões inflacionárias até mesmo com ridículos e insuficientes "vôos de galinha", os quais "obrigam" o Banco Central a manter as taxas de juros em patamares elevados, reforçando a apreciação do câmbio num cenário de ampla liquidez internacional.

Coisa nunca vista: há demanda efetiva internacional, há superávits comerciais apreciáveis, há recursos internacionais com liquidez, os impostos são pesados e os serviços e investimentos públicos são reduzidos; de outro lado, constituímos um dos países com maiores condições objetivas para o desenvolvimento e ao mesmo tempo temos uma necessidade histórica de inclusão social através deste processo. Só não o fazemos porque os interesses rentistas controlam alguns postos nas formas de governança da política econômica ${ }^{3}$. As instituições chaves na definição das políticas econômicas devem ser reformuladas, pois a moeda tendo função sistêmica não pode ser administrada para garantir lucros aos setores financeiros impedindo a geração de riqueza nova e ampliada.

Este insano modo de pensar a economia que protege politicamente os interesses rentistas está atrasando ainda mais o país. Certamente que no interior das atividades financeiras muitas são as pessoas que percebem haver um incomensurável potencial de

\footnotetext{
3 A respeito das reformas necessárias na Governança da Política Monetária Brasileira, ver o texto "O Regime de Metas de Inflação e a Governança da Política Monetária Brasileira: Análise e Propostas de Mudança" Oreiro e Passos (2005). Disponível em: http://www.economia.ufpr.br/publica/textos/2005/JLO 1703 2005.pdf.
} 
ganhos com a intermediação financeira voltada para a produção e o investimento. Não há país que possa crescer com o convite aos consumidores: "pague duas geladeiras e leve uma".

Em jornal recentemente publicado, curiosa notícia nos relatava que empresário chinês negociava com empresários europeus a aquisição de uma moderna fábrica de motores instalada no Brasil. Não, não se trata apenas de uma mudança de proprietários. A idéia é desmontar a fábrica inteira e remontá-la na China, aonde há dinamismo econômico. É apenas um sinal, visto que o fato pode inclusive não se concretizar. Mas quando empresários, comprador e vendedor estabelecem tal possibilidade de negócio, não estamos apenas "ficando para trás" porque não crescemos como outros países. Ao não crescermos por mais algum tempo, as atuais instalações do parque industrial brasileiro, pelas pálidas performances que produz e menores investimentos que o ambiente econômico estimula, vão se reduzindo. Este caminho já estamos trilhando: é a desindustrialização precoce.

Este processo de desindustrialização será ainda mais acelerado caso seja implantada uma nova rodada de desoneração tributária das importações, como já se especula em alguns círculos governamentais. Neste contexto de desigualdade competitiva a que está submetida a indústria brasileira - desigualdade essa gerada pela combinação perversa entre câmbio valorizado, juros elevados, impostos exorbitantes e infra-estrutura deficiente - o objetivo de tal medida só pode ser a destruição do parque industrial brasileiro.

Se a essência das atuais políticas não for modificada com urgência, a indústria brasileira estará condenada a um processo de definhamento, o qual terminará por enterrar qualquer possibilidade de retomada sustentada do crescimento da economia brasileira. 